\title{
Circular RNA_0074027 participates in cell proliferation, apoptosis and metastasis of colorectal cancer cells through regulation of miR-525-3p
}

\author{
GANG XIONG，JUN ZHANG，YICHAO ZHANG，XIAO PANG，BIAO WANG and YONGCHUAN ZHANG \\ Department of General Surgery, Dazhou Central Hospital, Dazhou, Sichuan 635000, P.R. China
}

Received July 29, 2020; Accepted January 21, 2021

DOI: $10.3892 / \mathrm{mmr} .2021 .11963$

\begin{abstract}
The present study aimed to elucidate the biological function of circular RNAs (circRNA) 0074027 in colorectal cancer (CRC). The expression of circRNA-0074027 in CRC tissues and cells was determined by reverse transcription-quantitative PCR. The in vitro experiments, including Cell Counting Kit-8 (CCK-8) assay, 5-Ethynyl-2'-deoxyuridine assay, flow cytometry and Transwell assay, were applied to evaluate cell proliferation, apoptosis and metastasis ability respectively following downregulation of circRNA-0074027. The correlation between circRNA-0074027 and micro (mi)RNA-525-3p was determined via dual-luciferase reporter assay. Finally, western blotting was used to explore the possible regulatory mechanism. CircRNA-0074027 was upregulated in CRC tissues, while miR-525-3p expression was reduced. In addition, patients with CRC and circRNA-0074027 overexpression were more likely to have low tumor differentiation, lymph node metastasis and advanced TMN stage. Deletion of circRNA-0074027 could suppress cell proliferation and metastasis through upregulating p53 expression and forbidding epithelial-mesenchymal transition signaling pathway. The addition of miRNA-525-3p inhibitors could reverse the anti-tumor effects induced by the deletion of circRNA-0074027. The downregulation of cirRNA_0074027 inhibited tumor progression via sponging miR-525-3p, which could be a promising treatment bio-marker for CRC.
\end{abstract}

\section{Introduction}

Colorectal cancer (CRC) is one of the commonest malignant tumors worldwide, with high mortality and morbidity $(1,2)$. Due to a lack of early symptoms and effective screening strategies, patients are commonly diagnosed with advanced

Correspondence to: Dr Yongchuan Zhang, Department of General Surgery, Dazhou Central Hospital, 56 Nanyuemiao Street, Dazhou, Sichuan 635000, P.R. China

E-mail: xiong123456g@126.com

Key words: circular RNA-0074027, microRNA-525-3p, colorectal cancer, cell proliferation, cell metastasis
CRC (2). Although there has been major progress in molecular target therapy and immunotherapy $(3,4)$, the overall survival time for patients with CRC is still not satisfactory. Therefore, it is essential to identify an effective bio-marker for CRC and explore its potential regulatory mechanism.

Circular RNAs (circRNAs), a novel type of non-coding RNA, are characterized as closed ring structure without 5' caps or 3' poly-A tails $(5,6)$. Emerging studies have shown that circRNAs may serve a function in the regulation of physiological and pathological processes via serving as microRNA (miRNA) sponges (7-9). A number of circRNAs are believed to serve a function as a tumor promoter or a tumor inhibitor in various cancer progression, including liver, ovarian and lung cancer (10-12). For example, silencing of circRNA-0060428 can inhibit cell growth in osteosarcoma by regulating the miR-375/RPBJ axis (13). CircRNA-0003645 can sponge miR-1229 and then promote hepatocellular carcinoma progression (14). However, the biological role of circRNAs in the development of CRC remains to be elucidated.

CircRNA-0074027 is a newly discovered competing endogenous (ce)RNA, which is oriented from chr5:134363423134369964. The biological role of circRNA-0074027 in malignant transfection has been explored $(15,16)$. Gao et al $(16)$ reported that circRNA-0074027 is upregulated in lung cancer and its overexpression can promote cell growth and metastasis ability via regulation of the $\mathrm{miR}-185-3 \mathrm{p} /$ bromodomain-containing protein 4/MAPK-activating death domain protein axis. In addition, Qian et al (15) demonstrated that the deletion of circRNA-0074027 can inhibit glioblastoma cell proliferation and metastasis by regulating the miR-518a-5p/IL17RD signaling pathway. However, it remains to be fully elucidated whether circRNA-0074027 serves as a tumor promoter in CRC progression.

The present study detected the expression of circRNA0074027 in CRC tissue samples and further investigated the role of circRNA-0074027 in oncogenesis. In vitro experiments were performed to identify the cell apoptosis rate, cell proliferation and metastasis ability. In addition, miR-525-3p was identified as a downstream target gene of circRNA-0074027 by bioinformatics analysis and the relationship was further confirmed by dual-luciferase reporter assays. Taken together, circRNA-0074027 is a promising bio-marker in CRC. 


\section{Materials and methods}

Patient tissue samples. A total of 60 paired CRC tissue and normal tissue samples were obtained from the patients with CRC who underwent surgery at Dazhou Central hospital between January 2014 and January 2018. The inclusion criteria were: i) Age $>18$ and $<80$ years; ii) written informed consent; and iii) primary CRC confirmed by pathological examination. The exclusion criteria were: i) Patients with other malignant diseases and ii) patients with previous neoadjuvant chemotherapy or radiotherapy. All samples were preserved in liquid nitrogen following histological confirmation by experienced pathologists. Written informed consent was sought from the participants before the samples were obtained. The present study was approved by the Ethical Committees of Dazhou Central Hospital (approval no. KY2020-086-01).

Cell culture. Normal epithelial cells (FHC) and CRC cancer cells (Caco-2, LoVo, SW480, HCT-116 and HCT-8), as well as 293T cell lines were acquired from American Type Culture Collection. All cell lines were incubated in $10 \%$ fetal bovine serum (FBS; Thermo Fisher Scientific, Inc.) supplemented with DMEM medium (Thermo Fisher Scientific, Inc.) under standard culture conditions $\left(5 \% \mathrm{CO}_{2}\right.$ and $\left.37^{\circ} \mathrm{C}\right)$.

RNA transfection. Small interfering (si) RNA against circRNA-0074027 (si-circRNA-0074027-1 and si-circRNA-0074027-2) and its paired control (si-Control), as well as miR-525-3p inhibitors and its negative control (miR-525-3p NC) were acquired from Shanghai GenePharma Co., Ltd. Lipofectamine ${ }^{\circledR} 3000$ (Invitrogen; Thermo Fisher Scientific, Inc.) was used for cell transfection. In brief, Lipofectamine ${ }^{\circledR} 3000$ was incubated with miRNA inhibitor at a concentration of $100 \mathrm{nmol} / \mathrm{l}$ or siRNAs at a concentration of $200 \mathrm{nmol} / \mathrm{l}$ for $20 \mathrm{~min}$ at room temperature and the complex was then added to each well of a 6-well plate. Following transfection for $24 \mathrm{~h}$, the subsequent experiments were performed. The sequences were: si-circRNA-0074027-1 (5'-GCGTGC TAAGCACCTGGCGCA-3'), circRNA-0074027-2 (5'-GTG CTAAGCACCTGGCGCAGG-3') and miR-525-3p inhibitor (5'-CGCUCUAAAGGGAAGCGCCUUC-3').

Reverse transcription-quantitative (RT-q) PCR. According to the manufacturer's protocols, TRIzol ${ }^{\circledR}$ (Thermo Fisher Scientific, Inc.) was used for total RNA extraction from tissue and cell samples. Subsequently, total RNA $(1 \mu \mathrm{g})$ was transcribed to cDNA via using PrimeScript RT Master Mix (Takara Biotechnology Co., Ltd.). The temperature and duration of RT were: $37^{\circ} \mathrm{C}$ for $30 \mathrm{sec}$, followed by $85^{\circ} \mathrm{C}$ for $5 \mathrm{sec}$ and $4^{\circ} \mathrm{C}$ for $10 \mathrm{~min}$. The cDNA (10 $\left.\mathrm{ng}\right)$ was subjected to qPCR (Bio-Rad Laboratories, Inc.) using SYBR Premix Ex Taq II kit (Takara Biotechnology Co., Ltd.), and the reaction volume was $10 \mu \mathrm{l}$. The thermocycling conditions were: $95^{\circ} \mathrm{C}$ for $30 \mathrm{sec}$, followed by 40 cycles of $95^{\circ} \mathrm{C}$ for $5 \mathrm{sec}$ and $60^{\circ} \mathrm{C}$ for $40 \mathrm{sec}$. GAPDH was used as reference gene and relative mRNA expression changes were calculated by $2^{-\Delta \Delta C q}$ method (17). The primer sequences used are shown in Table I.

Cell proliferation assay. A CCK-8 kit (Dojindo Molecular Technologies, Inc.) was used to assess the cell viability at different time points. A 5-Ethynyl-2'-deoxyuridine (EdU) cell proliferation kit (Guangzhou RiboBio Co., Ltd.) was used to identify the EdU positive rate of CRC cells.

Flow cytometry. An Annexin V-FITC/PI apoptosis detection kit (Nanjing KeyGen Biotech Co., Ltd.) was used for the detection of the cell apoptosis rate. According to the manufacturer's protocols, the transfected cells were collected and suspended with binding buffer. Then, Annexin V-FITC and propidium iodide were added to the buffer. Subsequently, the mixture was shielded from light and incubated at room temperature for $15 \mathrm{~min}$. Subsequently, the samples were detected by flow cytometer (BD FACSCelesta ${ }^{\mathrm{TM}}$ Flow Cytometer; BD Biosciences), and early plus late apoptotic cells were analyzed using FlowJo software (FlowJo LLC).

Transwell assay. For the cell migration assay, the transfected cells were suspended in DMEM without FBS, added into the upper Transwell chambers $(0.8 \mu \mathrm{m}$; Corning, Inc.) and incubated for $48 \mathrm{~h}$. The lower chamber was filled with DMEM supplemented with $20 \%$ FBS. The migrated and invasive CRC cells were fixed with $4 \%$ methanol for $10 \mathrm{~min}$, stained with crystal violet for $10 \mathrm{~min}$ at room temperature, and finally captured with a light microscope. For the cell invasion assay, the filter membranes were precoated with Matrigel ${ }^{\circledR}$ (Corning, Inc.) at $37^{\circ} \mathrm{C}$ for $30 \mathrm{~min}$, and the other steps were performed as described in the migration assay.

Western blotting. The un-transfected and transfected cells were lysed using RIPA buffer (Beyotime Institute of Biotechnology), followed by homogenization at $4^{\circ} \mathrm{C}$ for 10 min. Protein concentration was evaluated with BCA Protein Assay kit (Beyotime Institute of Biotechnology). Equal amounts $(20 \mu \mathrm{g})$ of proteins were loaded and subjected to $10 \%$ SDS-PAGE electrophoresis, followed by transferred onto polyvinylidene fluoride membranes. The membranes were blocked with $10 \%$ bovine serum albumin (Beijing Solarbio Science \& Technology Co., Ltd.) for $1 \mathrm{~h}$ at room temperature. Subsequently, the membranes were incubated with primary antibodies: p-53 (cat. no. ab32389), Bcl-2 (cat. no. ab32124), Bax (cat. no. ab32503), E-cadherin (cat. no. ab11512), N-cadherin (cat. no. ab245117), Vimentin (cat. no. ab16700) and GAPDH (cat. no. ab9485; all 1:1,000 dilution; Abcam) overnight at $4^{\circ} \mathrm{C}$. Subsequently, proteins were incubated with the goat anti-rabbit IgG H\&L (HRP; cat. no. ab6721; 1:2,000 dilution; Abcam) for $1 \mathrm{~h}$ at room temperature. Finally, the protein bands were then analyzed with super sensitive ECL luminescence reagent (Dalian Meilun Biology Technology Co., Ltd.). The protein expression levels were detected using a chemi-luminescence detection system with Quantity One software (v3.0; Sigma-Aldrich; Merck KGaA).

Prediction of downstream molecules regulated by circRNA0074027. A publicly available bioinformatics algorithm (Starbase 2.0) was utilized to predict the downstream miRNAs of circRNA-0074027 (9).

Dual-luciferase reporter assays. The wild-type (WT) and mutant (MUT) circRNA-0074027 fragments were constructed and inserted into the pmirGLO vector (Ybscience). The WT 
Table I. Sequences of oligomers and primers used in the present study.

\begin{tabular}{|c|c|}
\hline Name & Sequence $\left(5^{\prime}-3^{\prime}\right)$ \\
\hline $\begin{array}{l}\text { CircRNA-0074027 } \\
\text { forward }\end{array}$ & GATTTCCCGACCCCGTACAA \\
\hline $\begin{array}{l}\text { CircRNA-0074027 } \\
\text { reverse }\end{array}$ & GGGGTGTTCTGAGATGGACC \\
\hline miR-525-3p forward & GGAAGGCGCTTCCCTTT \\
\hline miR-525-3p reverse & GTTGTGGTTGGTTGGTTTGT \\
\hline GAPDH forward & CCTTCCGTGTCCCCACT \\
\hline GAPDH reverse & GCCTGCTTCACCACCTTC \\
\hline
\end{tabular}

circRNA, circular RNA; miR, microRNA.

and MUT plasmids, as well as miR-525-3p inhibitor and miR-525-3p NC, were co-transfected into $293 \mathrm{~T}$ cells using Lipofectamine ${ }^{\circledR} 3000$ (Invitrogen; Thermo Fisher Scientific, Inc.). After $24 \mathrm{~h}$, the firefly and Renilla luciferase activities were measured using a dual-luciferase reporter assay system (Promega Corporation) according to the manufacturer's instructions.

Statistical analysis. All experiments were repeated at least three times. The data are shown as the mean \pm standard deviation. Comparisons between two groups were performed using Student's t-test. In addition, the samples were divided into a high and a low expression group according to the median value of circRNA-0074027 expression and $\chi^{2}$ test was performed to analyze the relationship between the circRNA-0074027 expression and clinicopathological characterization of patients with CRC. The data among three or more groups were performed using one-way ANOVA followed by Fisher's least significant difference post hoc test. The correlation between circRNA-0074027 and miR-525-3p were analyzed by Pearson's correlation. Statistical analyses were performed using SPSS 20.0 (IBM Corp.). $\mathrm{P}<0.05$ was considered to indicate a statistically significant difference.

\section{Results}

CircRNA-0074027 expression is increased in CRC tissue samples. Results comparing circRNA-0074027 expression levels in CRC tissues samples and samples obtained from adjacent normal tissues revealed that there was an overexpression of circRNA-0074027 in the CRC tissues (Fig. 1A). Subsequently, it was discovered that among 60 paired tissue samples, almost $73.3 \%$ (44/60) demonstrated higher circRNA-0074027 expression in CRC tissues (Fig. 1B). Next, these 60 patients with CRC were divided into two groups, including circRNA-0074027 high and low expression group, based on the median value of circRNA-0074027 expression. According to the results of statistical analysis, it was found that the circRNA-0074027 expression was closely related to the differential status $(\mathrm{P}=0.001), \mathrm{N}$ stage $(\mathrm{P}=0.004)$, vascular invasion $(\mathrm{P}=0.016)$, tumor size $(\mathrm{P}<0.001)$ and $\mathrm{TNM}$ stage $(\mathrm{P}=0.02$; Table II). Similarly, the data revealed that patients with CRC and circRNA_0047027 overexpression were more
Table II. Correlation between the clinicopathological data and circRNA-0074027 expression of in colorectal cancer $(n=60)$.

\begin{tabular}{|c|c|c|c|c|}
\hline \multirow[b]{2}{*}{ Characteristics } & \multirow[b]{2}{*}{$\mathrm{n}$} & \multicolumn{2}{|c|}{$\begin{array}{c}\text { circRNA- } \\
0074027 \\
\text { expression }\end{array}$} & \multirow[b]{2}{*}{ P-value } \\
\hline & & High & Low & \\
\hline \multicolumn{5}{|l|}{ Sex } \\
\hline Male & 27 & 12 & 15 & \multirow[t]{2}{*}{0.586} \\
\hline Female & 33 & 17 & 16 & \\
\hline \multicolumn{5}{|l|}{ Age } \\
\hline$<60$ years & 25 & 12 & 13 & \multirow[t]{2}{*}{0.879} \\
\hline$\geq 60$ years & 35 & 18 & 17 & \\
\hline \multicolumn{5}{|l|}{ Differential status } \\
\hline Moderate/well & 20 & 13 & 7 & \multirow[t]{2}{*}{0.001} \\
\hline $\begin{array}{l}\text { Undifferentiated/ } \\
\text { poorly }\end{array}$ & 40 & 9 & 31 & \\
\hline \multicolumn{5}{|l|}{ Vascular invasion } \\
\hline Negative & 22 & 14 & 8 & \multirow[t]{2}{*}{0.016} \\
\hline Positive & 38 & 12 & 26 & \\
\hline \multicolumn{5}{|l|}{ Tumor size } \\
\hline$\leq 5 \mathrm{~cm}$ & 25 & 19 & 6 & \multirow[t]{2}{*}{$<0.001$} \\
\hline$>5 \mathrm{~cm}$ & 35 & 8 & 27 & \\
\hline \multicolumn{5}{|l|}{ N stage } \\
\hline No & 27 & 19 & 8 & \multirow[t]{2}{*}{0.004} \\
\hline N1-N3 & 33 & 11 & 22 & \\
\hline \multicolumn{5}{|l|}{ TNM stage } \\
\hline I-II & 24 & 16 & 8 & \multirow[t]{2}{*}{0.02} \\
\hline III-IV & 36 & 13 & 23 & \\
\hline \multicolumn{5}{|l|}{ Tumor location } \\
\hline Left colon cancer & 20 & 8 & 12 & \multirow[t]{3}{*}{0.625} \\
\hline Right colon cancer & 22 & 10 & 12 & \\
\hline Rectal cancer & 18 & 10 & 8 & \\
\hline
\end{tabular}

Significant differences are presented in bold. circRNA, circular RNA.

likely to have low tumor differentiation (Fig. 1C), lymph node metastasis (Fig. 1D) and advanced TMN stage (Fig. 1E). In summary, circRNA-0074027 might have a role as a tumor inhibitor role in CRC progression.

Knockdown of circRNA-0074027 suppresses CRC cell growth. Since the expression of circRNA-0074027 was reduced in CRC tissues, its expression was further detected in normal epithelial cells and five different CRC cell lines. When compared with normal epithelial cell lines (FHC), the expression of circRNA-0074027 was higher in CRC cell lines, especially in Caco-2 and LoVo cells (Fig. 2A). Therefore, the Caco-2 and LoVo cells were selected in the present study for future in vitro experiments. The expression of circRNA-0074027 in Caco-2 and LoVo cells was knocked down using RNA transfection (Fig. 2B and C). The results of CCK-8 assay displayed that silencing of circRNA-0074027 could markedly inhibit the cell 
A
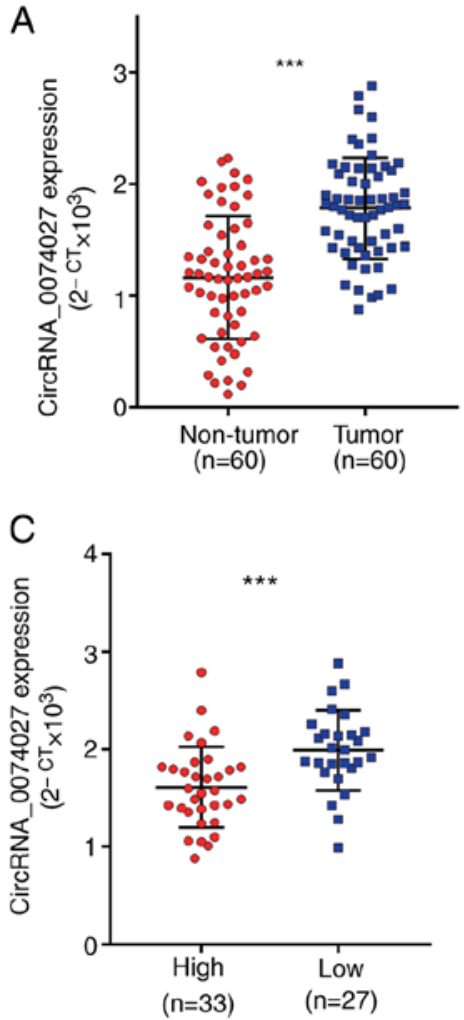

B
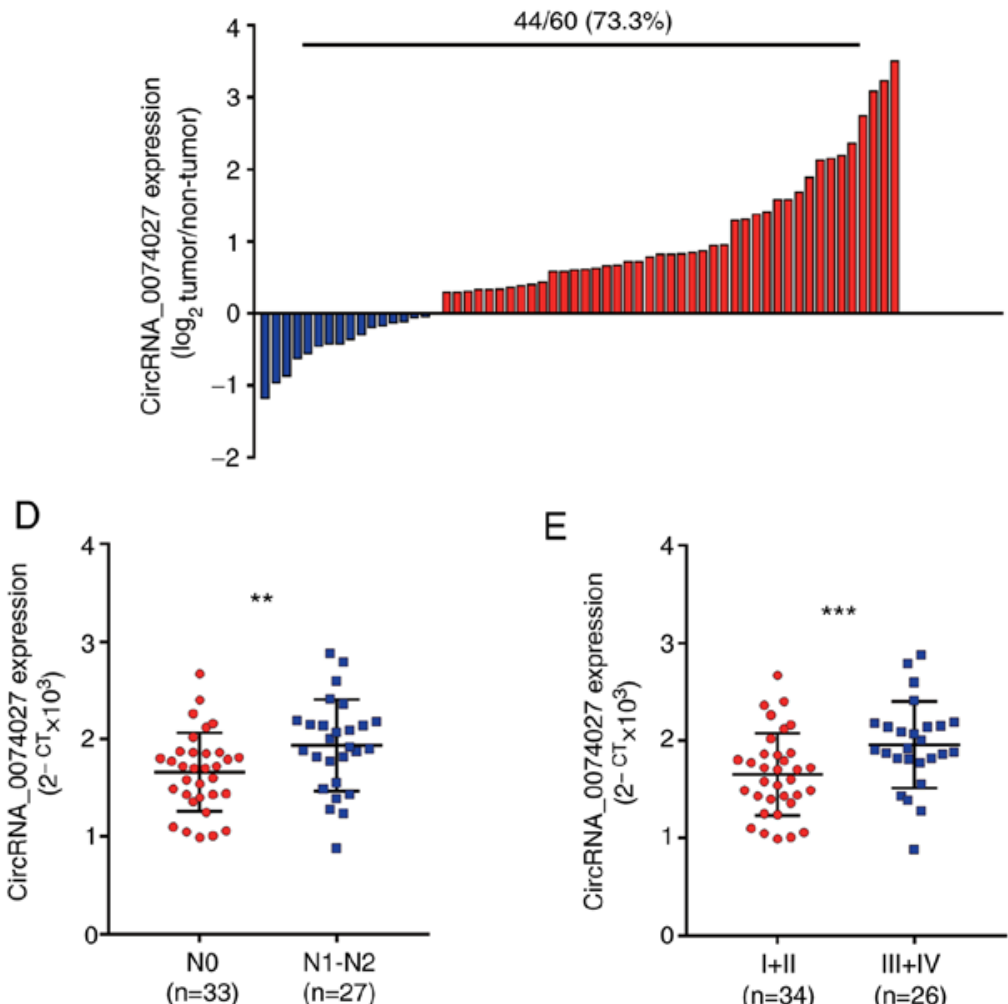

E

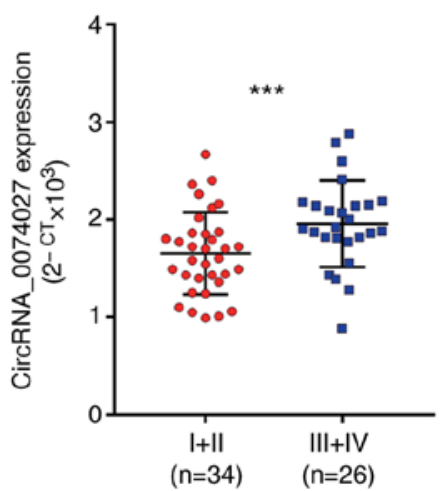

Figure 1. Expression of circRNA-0074027 is enhanced in CRC. (A) The expression of circRNA-0074027 in CRC tissues. (B) CircRNA-0074027 is upregulated (73.3\%; 44/60) in CRC. (C) Relationship between circRNA-0074027 expression and tumor differentiation. (D) The relationship between circRNA-0074027 expression and lymph node metastasis. (E) The relationship between circRNA-0074027 expression and TMN stage. ${ }^{* * *} \mathrm{P}<0.01,{ }^{* * *} \mathrm{P}<0.001$. circRNA, circular RNA; CRC, colorectal cancer.

growth rate in both of HGC-27 and AGS cells (Fig. 2D and F). Consistent with the previous results, the EdU assay also indicated that there were fewer EdU-positive Caco-2 cells in siRNA-circRNA-0074027-1 and siRNA-circRNA-0074027-2 group than that in si-Control group (Fig. 2E). Additionally, EdU-positive LoVo cells in siRNA-circRNA-0074027-1 and siRNA-circRNA-0074027-2 group were fewer compared with the si-Control group (Fig. 2G). In total, silencing of circRNA-0074027 could suppress cell growth rate in CRC.

Knockdown of circRNA-0074027 increases cell apoptosis rate via activating the p53 pathway. As circRNA-0074027 upregulation could suppress cell proliferation ability in CRC, the changes of apoptosis level with low expression of circRNA-0074027 required further research. Therefore, in current study, the cell apoptosis rate was detected by flow cytometry experiments. As shown in Fig. 3A, the total cell apoptosis rate of Caco-2 cells in siRNA-circRNA-0074027-1 and siRNA-circRNA-0074027-2 group were higher compared with the si-Control group. Similarly, silencing of circRNA-0074027 could induce more apoptosis in LoVo cells compared with the si-Control group (Fig. 3B).

Western blotting was performed to identify the potential mechanism of the downregulation of circRNA-0074027 on cell apoptosis. The downregulation of circRNA-0074027 could significantly increase p53 and Bax proteins expression, while reducing the expression of anti-apoptosis protein $\mathrm{Bcl}-2$ compared with the si-Control group (Fig. 3C and D). In all, these data consistently displayed that the downregulation of circRNA-0074027 could significantly promote cell apoptosis via the regulation of p53 signaling pathway in CRC.

Knockdown of circRNA-0074027 inhibits cell metastasis via interfering with the epithelial to mesenchymal transition (EMT) signaling pathway. Statistical analysis of data revealed that circRNA-0074027 expression was associated with lymph node metastasis in CRC. Therefore, Transwell assay was performed to determine the involvement of circRNA-0074027 in CRC cell metastasis. As shown in Fig. 4A, the number of cells migrating and invading decreased markedly following downregulation of the expression of circRNA-0074027 in Caco-2 cells compared with si-Control group. Fig. 4B demonstrates that the silencing of circRNA-0074027 could significantly suppress cell migration and invasion ability in LoVo cells compared with the control group. The results of western blot analysis demonstrated that there was an increase of epithelial-like phenotype protein (E-cadherin) and a decrease of mesenchymal phenotype proteins $(\mathrm{N}$-cadherin and vimentin) when circRNA-0074027 was downregulated (Fig. 4C and D). Taken together, these data suggested that knockdown of circRNA-0074027 suppresses CRC cell metastasis ability by inhibiting the EMT pathway.

miR-525-3p is the target gene of circRNA-0074027. Previous studies (18-20) have revealed that circRNAs may act as miRNA sponges in regulation of CRC progression. In the present 
A

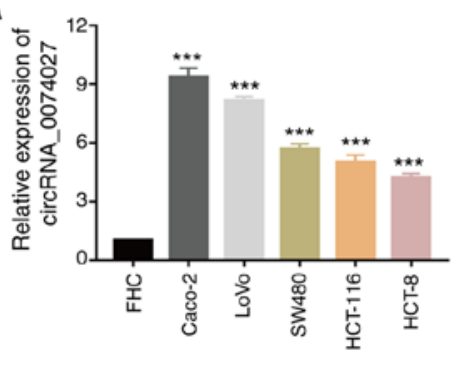

B

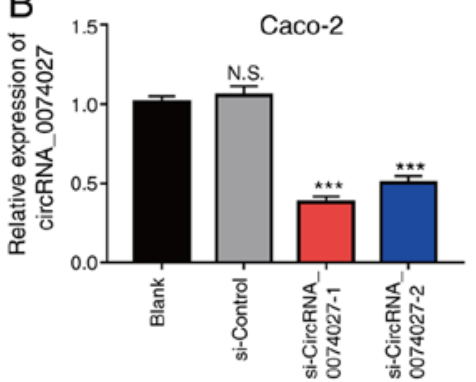

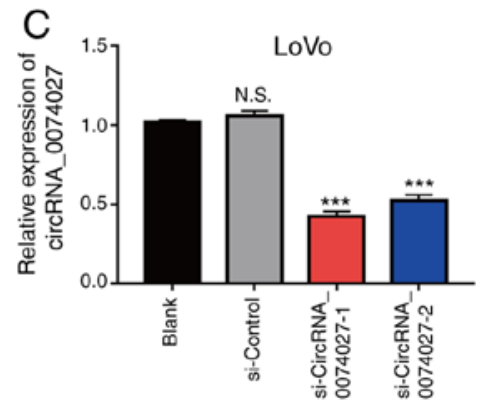

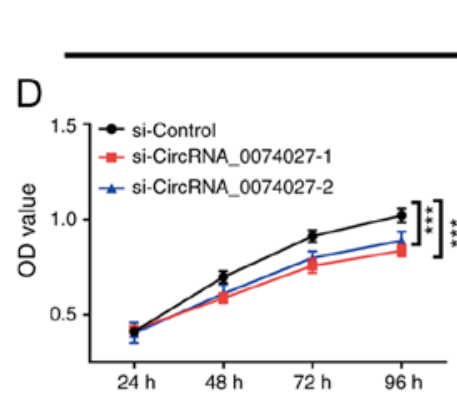

E

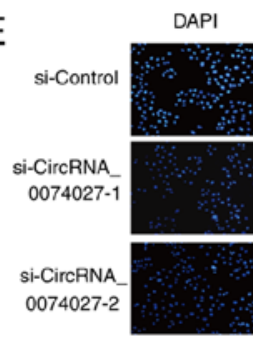

Caco-2

EdU Overlay
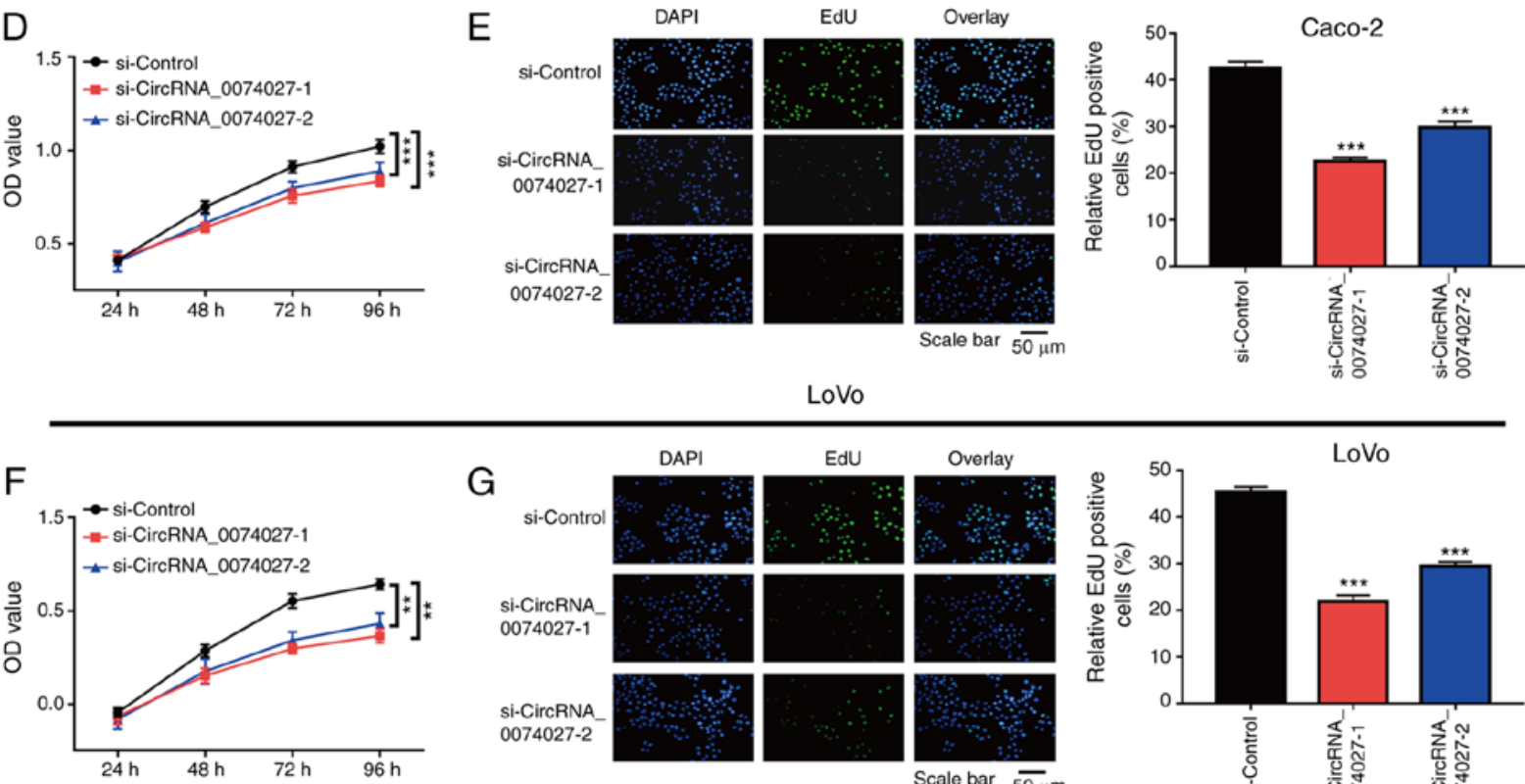

G
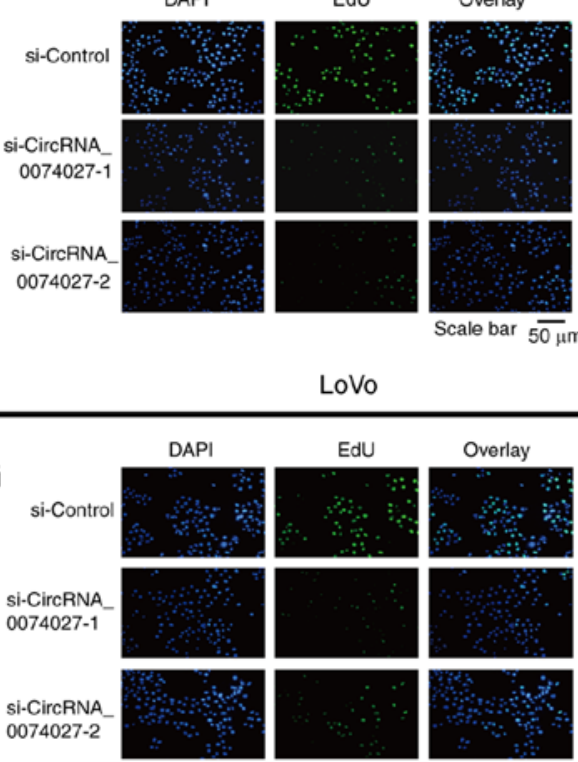

LoVo

LoVo
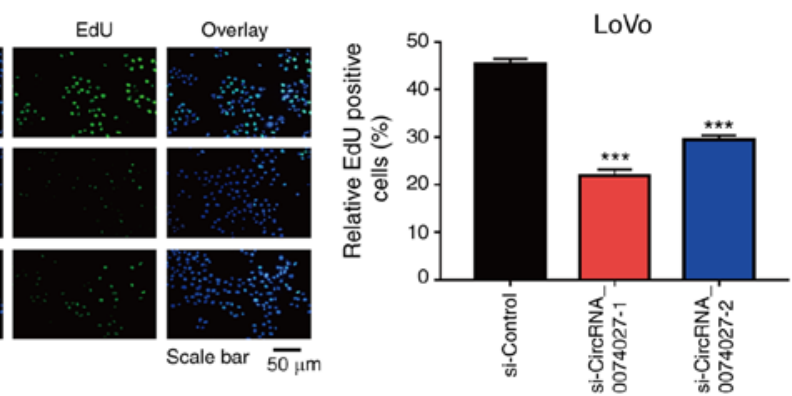

Figure 2. Downregulation of circRNA 100395 suppresses CRC cell proliferation. (A) The expression of circRNA-0074027 in CRC cells. Successful construction of circRNA-0074027-downregulated (B) Caco-2 and (C) LoVo cells. The cell proliferation ability of (D) Caco-2 and (F) LoVo cells upon inhibiting circRNA-0074027 expression. 5-Ethynyl-2'-deoxyuridine assay of (E) Caco-2 and (G) LoVo cells upon inhibiting circRNA-0074027 expression. Every experiment was repeated three times. ${ }^{* *} \mathrm{P}<0.01,{ }^{* * *} \mathrm{P}<0.001$. circRNA, circular RNA; CRC, colorectal cancer; N.S., no significance; si, short interfering.

study, miR-525-3p was proposed as the downstream gene of circRNA-0074027 based on the results of bioinformatics algorithms (Starbase.2). Subsequently, we discovered that the low-expression of miR-525-3p accounted for $80.0 \%$ (48/60) of the CRC tissue samples (Fig. 5A). The potential binding site between circRNA-0074027 and miR-525-3p was predicted as shown in Fig. 5B. Similarly, the results of RT-qPCR demonstrated that miR-525-3p was significantly downregulated in CRC tissue samples (Fig. 5C). Pearson correlation analysis revealed that the circRNA-0074027 expression was negatively correlated with the expression of miR-525-3p in CRC (Fig. 5D, $r=-0.5483, \mathrm{P}<0.0001)$. To further explore their association, luciferase reporter assay was performed and the results indicated that miR-525-3p mimics could markedly decrease the luciferase activity of wild-type circ_0074027, but with no effect on MUT circ_0074027 (Fig. 5E). The results of RT-qPCR indicated that miR-525-3p inhibitor could significantly downregulate the expression of miR-525-3p in Caco-2 cells, when compared with the control group (Fig. 5F). In addition, RT-qPCR assay was performed to determine the expression of miR-525-3p in Caco-2 cells. Notably, both si-Circ_0074027-1 and si-Circ_0074027-2 groups demonstrated higher expression of miR-525-3p in comparison with si-Control group, with the si-Circ_0074027-1 group showing the highest expression (Fig. 5G). Thus si-circRNA-0074027-1 Caco-2 cells were suggested as ideal for future rescue experiments. To elucidate the potential regulatory role of miR-525-3p, the miR-525-3p inhibitor was used to decrease the intra-cellular miR-525-3p expression in Circ_0074027 downregulated Caco-2 cells and this was verified with the RT-qPCR assay (Fig. 5H). These data consistently revealed that miR-525-3p would be direct target gene of circRNA-0074027 in CRC.

Knockdown of miR-525-3p expression reverses the anti-tumor effects induced by the overexpression of circRNA-0074027 in $C R C$. To explore the regulatory role of miR-525-3p in the regulation of CRC progression, miR-525-3p inhibitors were added to inhibit the expression of miR-525-3p in circRNA-0074027-downregulated Caco-2 cells. As the results of CCK-8 and EdU assay demonstrated, the effects of circRNA-0074027 downregulation on suppression of cell proliferation could be rescued by adding miR-525-3p inhibitors (Fig. 6A and B). Addition of miR-525-3p inhibitors may also reduce the cell apoptosis rate in the si-circRNA-0074027-1 
A

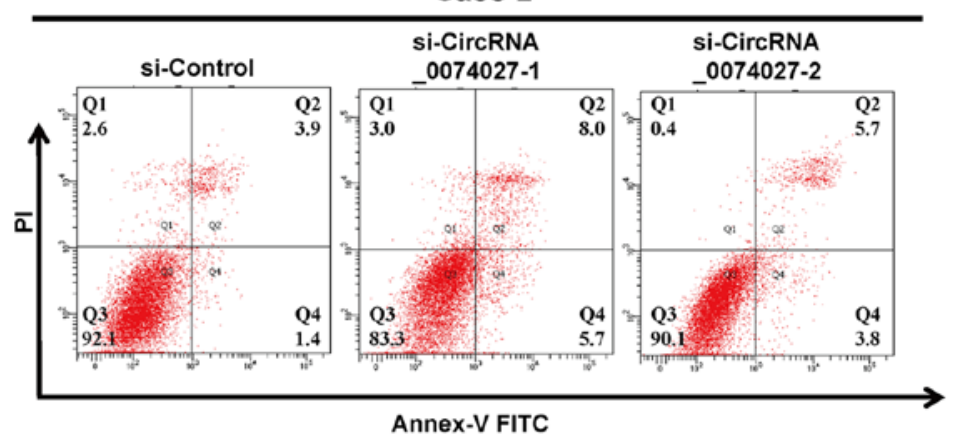

B

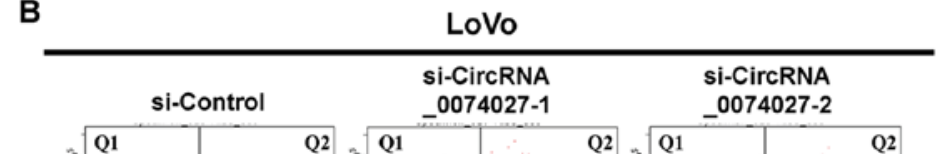

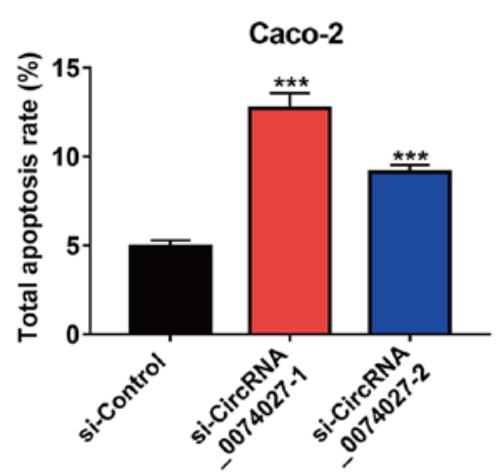

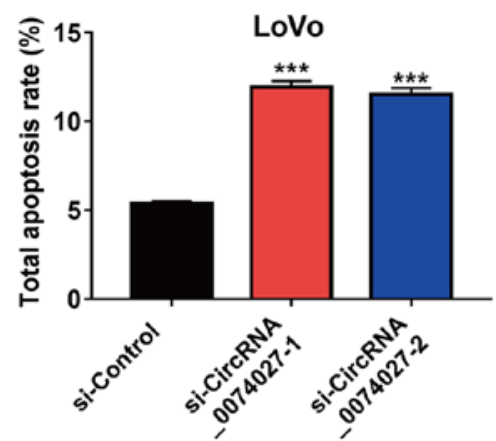

C

Caco-2

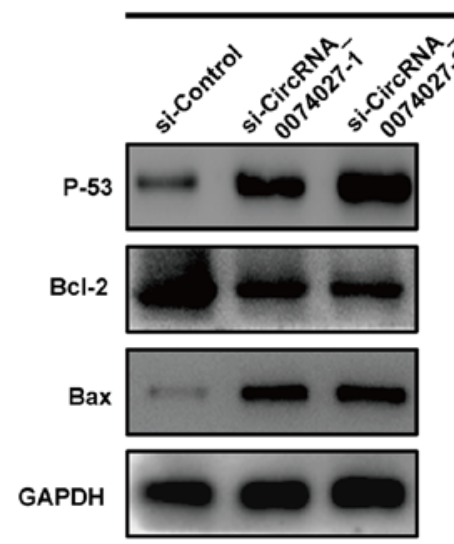

D

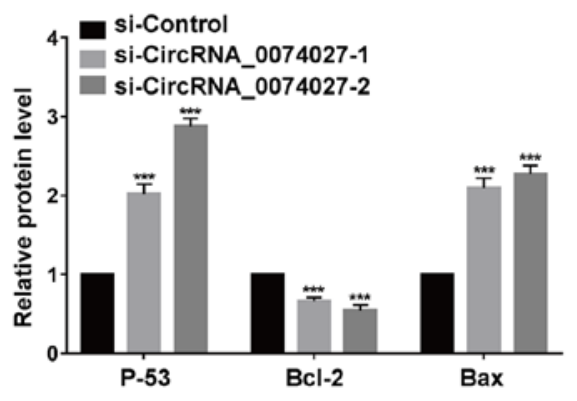

Caco-2
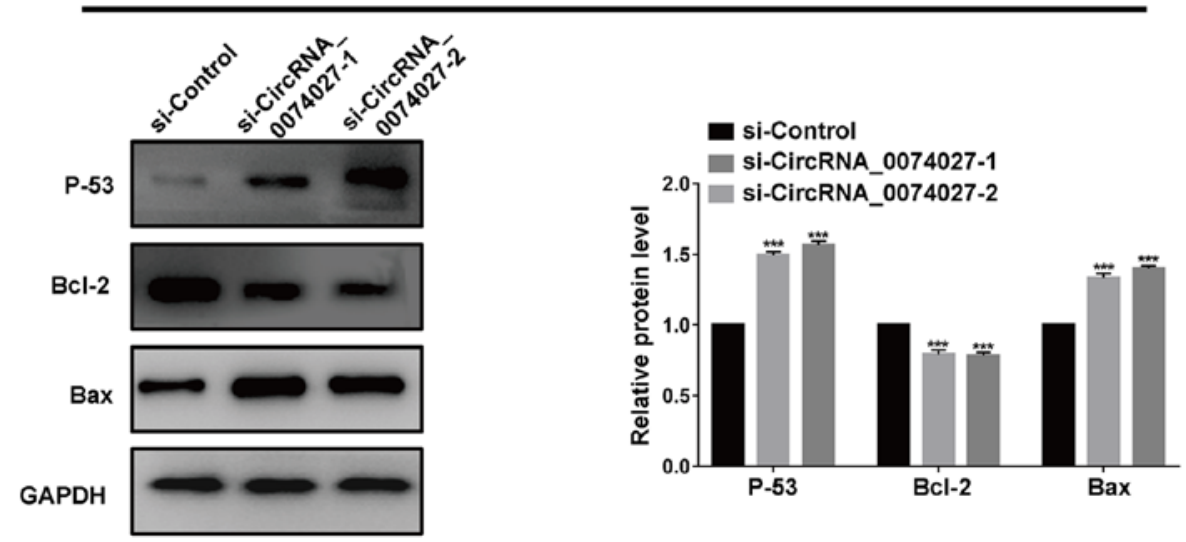

Figure 3. Downregulation of circRNA-0074027 promotes cell apoptosis in CRC. The cell apoptosis images (left) and statistical analysis (right) of (A) Caco-2 and (B) LoVo cells upon circRNA-0074027 downregulation. The total apoptosis rate includes cells in right quadrants (Q2 and Q4). Western blotting images of p53, Bcl-2 and Bax protein expression in (C) Caco-2 and (D) LoVo cells with circRNA-0074027 downregulation. Every experiment was repeated three times. ${ }_{* * * *} \mathrm{P}<0.001$. circRNA, circular RNA; CRC, colorectal cancer; si, short interfering. 
A Caco-2
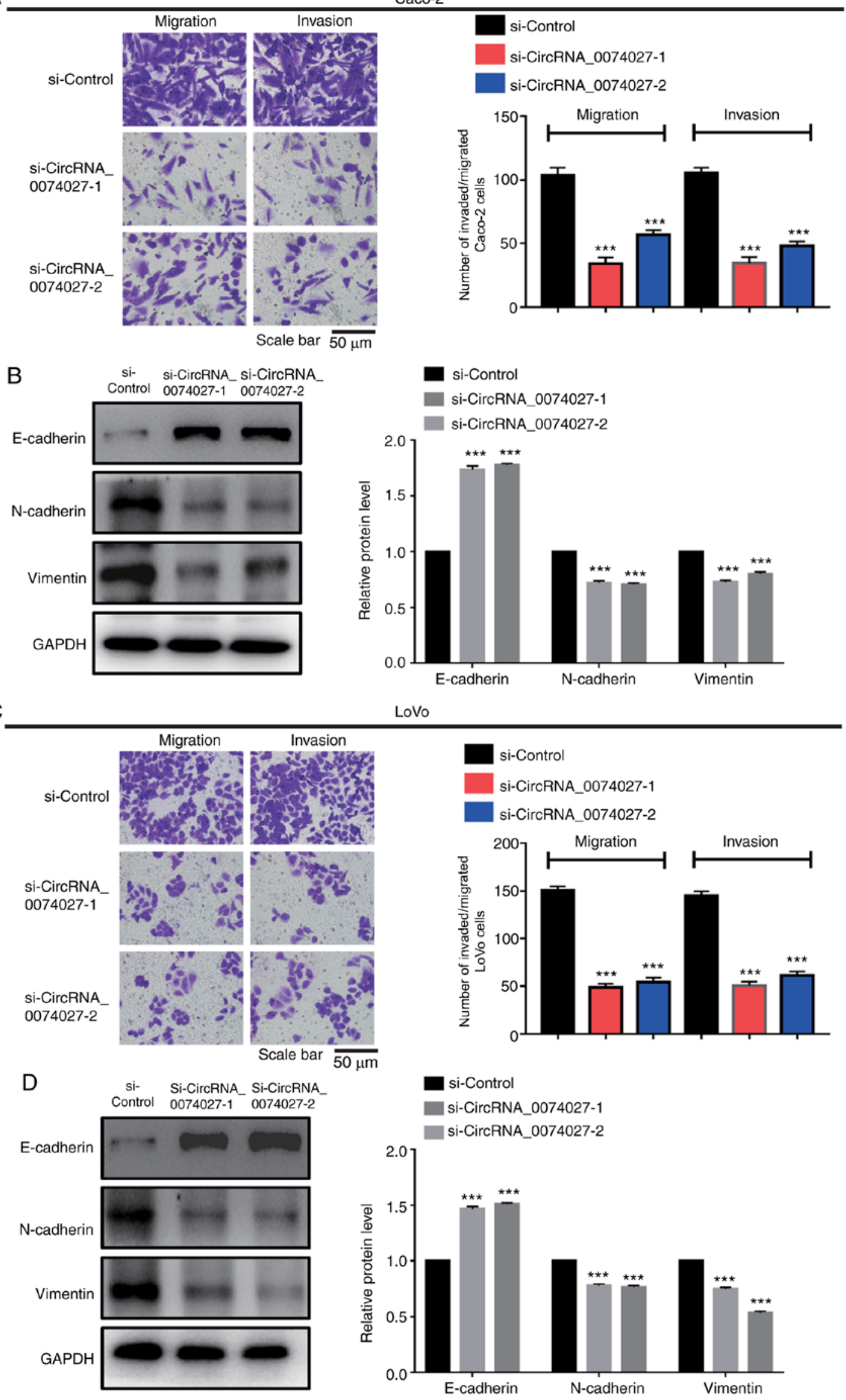

Figure 4. Downregulation of circRNA-0074027 inhibits cell metastasis in CRC. The cell migration and invasion images (left) and statistics analysis (right) of (A) Caco-2 and (B) LoVo cells upon downregulation of circRNA-0074027. Western blotting images of EMT signaling pathway related proteins expression in (C) Caco-2 and (D) LoVo cells when circRNA-0074027 is downregulated. Every experiment was repeated three times. ${ }^{* * * *} \mathrm{P}<0.001$. circRNA, circular RNA; CRC, colorectal cancer; si, short interfering. 


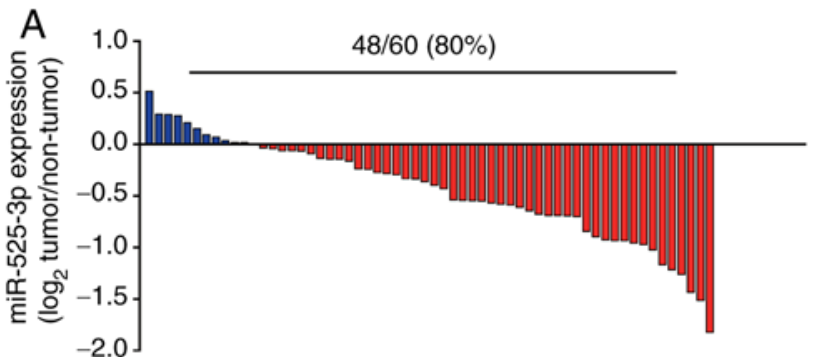

B hsa-circ_0074027-WT 5'..UAGGCCCGGCCGAGAGCGCCUUA...3' hsa-miR-525-3p 3'...GCGAGAUUUCCCUUCGCGGAAG...5' hsa-circ_0074027-MUT 5'...UAGGCCCGGCCGAGACGCGGAAG...3'
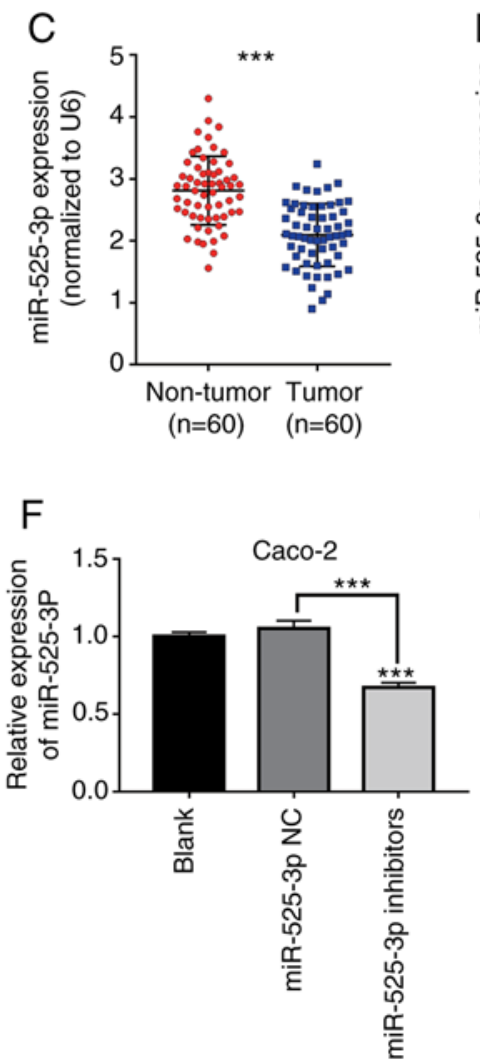
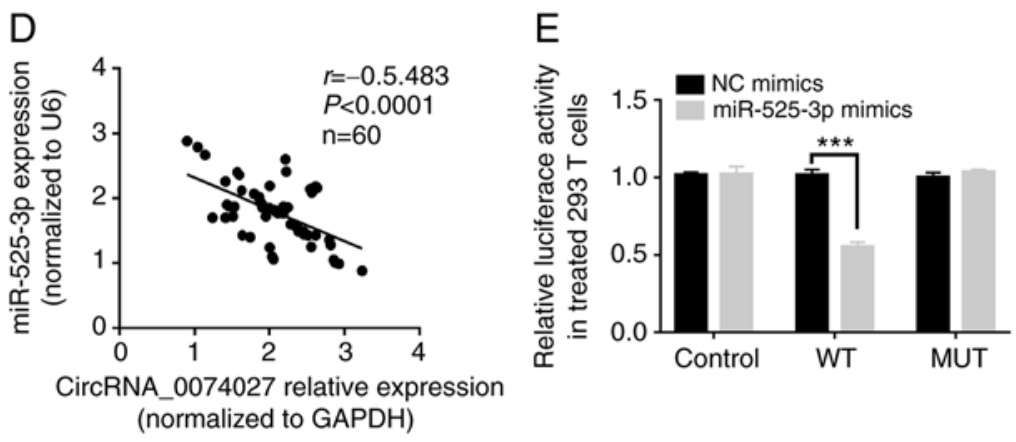

G

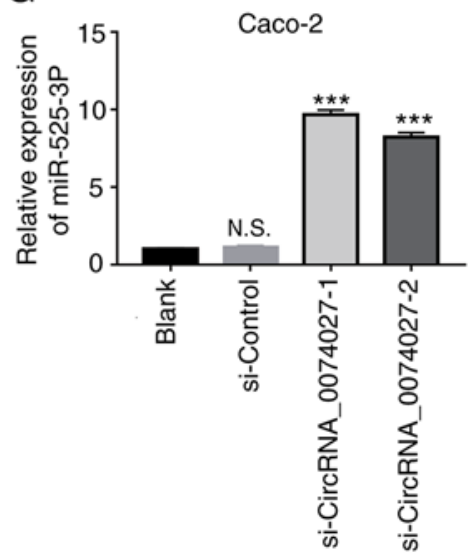

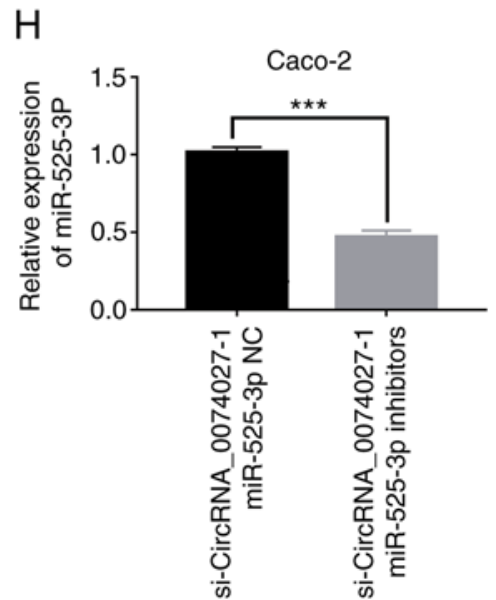

Figure 5. miR-525-3p is a downstream target gene of circRNA-0074027. (A) miR-525-3p is downregulated in CRC tissues. (B) The predicted 3'UTR binding regions of circRNA-0074027 on miR-525-3p. (C) The expression of miR-525-3p in CRC tissues. (D) The Pearson correlation analysis between the miR-525-3p and circRNA-0074027 expression. (E) Relative luciferase activity in 293T cells following co-transfection. (F) The expression level of miR-525-3p in Caco-2 cells following treatment with miR-525-3p inhibitors, as detected by RT-qPCR. (G) The expression of miR-525-3p in circRNA_007402-downregulated Caco-2 cells. (H) The expression of miR-525-3p in circRNA_007402-downregulated Caco-2 cells following treatment with miR-525-3p inhibitors. ${ }^{* * *} \mathrm{P}<0.001$. miR, microRNA; circRNA, circular RNA; CRC, colorectal cancer; RT-qPCR, reverse transcription-quantitative PCR; N.S., no significance; si, short interfering; WT, wild-type; MUT, mutant; NC, negative control.

Caco-2 cells (Fig. 6C). Similarly, the western blotting results also revealed that when incubating with miR-525-3p inhibitors could lead to increased expression of p53 and Bax proteins but decrease Bcl-2 protein expression in si-circRNA-00074027-1 Caco-2 cells (Fig. 6D).

An increase in migrated and invasive Caco- 2 cells were was observed in si-circRNA-0074027-1 groups following the addition of miR-525-3p inhibitors (Fig. 6E). Furthermore, the EMT signaling pathway-related markers in CRC cells were also determined following adding miR-525-3p inhibitor. The addition of miR-532-3p could lead to decreased expression of E-cadherin proteins and an increased expression of $\mathrm{N}$-cadherin and Vimentin proteins in circRNA-0074027-low expression CRC cells (Fig. 6F). Therefore, these data revealed that downregulation of circRNA-0074027 could exert anti-tumor effects through sponging miR-525-3p in CRC.

\section{Discussion}

CRC is one of the most prevalent malignancies in the world $(1,2)$. The main strategies for CRC treatment include surgery, radiotherapy and chemotherapy, which have shown positive therapeutic effects in early-stage patients. However, due to the shortage of effective biomarkers, most patients are diagnosed with advanced CRC and thus have short survival periods (1). Therefore, the present study was designed to identify effective diagnosis and therapeutic bio-markers and determine their potential mechanism.

It is known that circRNAs are evolutionally conserved and more stable than other non-coding RNAs, suggesting that circRNAs might be the most suitable bio-markers for human diseases $(21-23)$. Several studies $(15,16,24)$ indicate that circRNA-0074027 is an important regulatory factor in the 

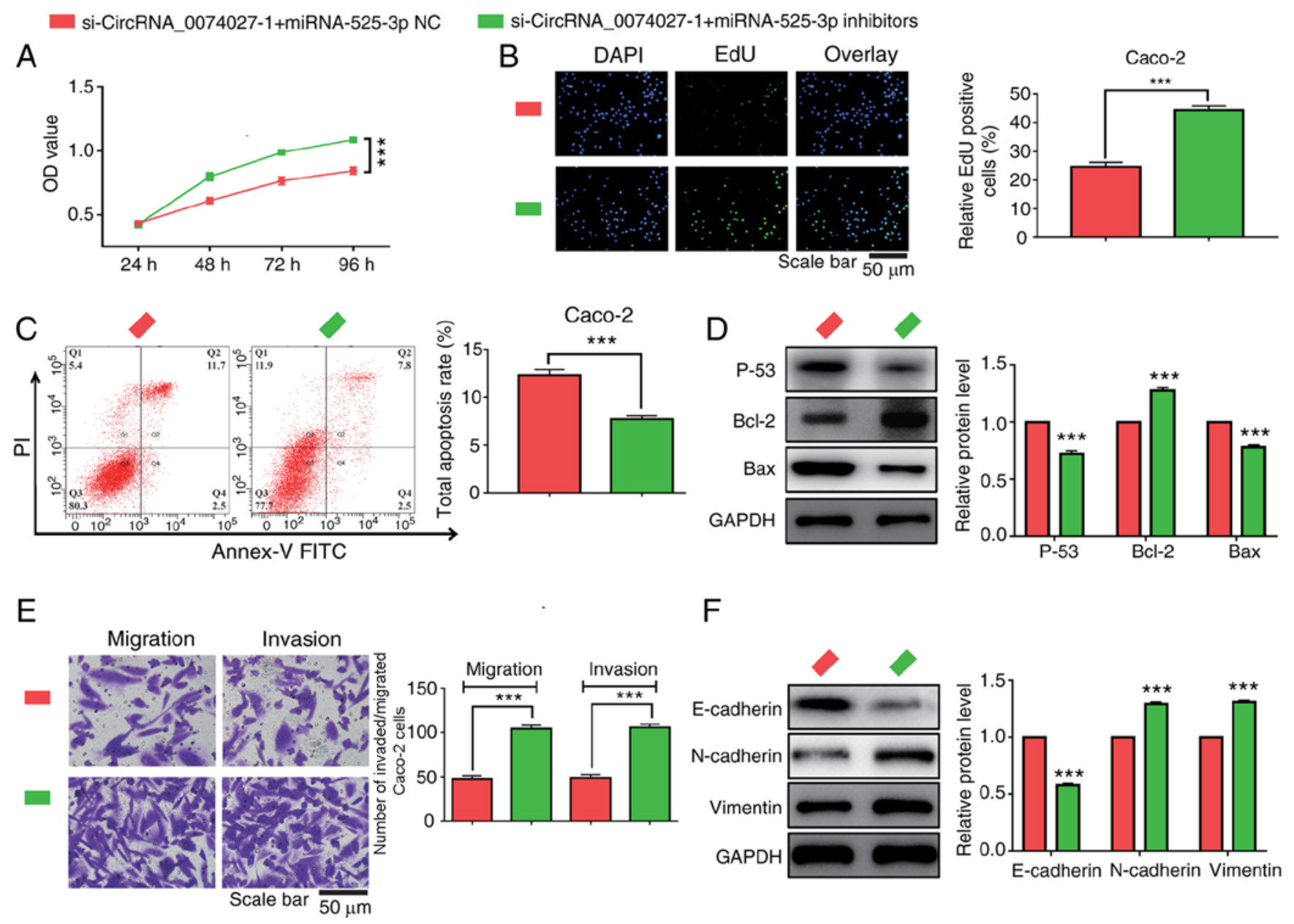

Figure 6. Downregulation of miR-525-3p rescues anti-tumor effects induced by depletion of circRNA-0074027. (A) Cell proliferation analysis of circRNA-0074027-downregulated Caco-2 cells. (B) 5-Ethynyl-2'-deoxyuridine assay of circRNA-0074027-downregulated Caco-2 cells. (C) Cell apoptosis rate of circRNA-0074027-downregulated Caco-2 cells. (D) Expression of p53, Bax and Bcl-2 proteins in circRNA-0074027-downregulated Caco-2 cells following addition of miR-135a-5p. (E) Cell migration and invasion of circRNA-0074027-downregulated Caco-2 cells. (F) Expression of epithelial to mesenchymal transition signaling pathway-related proteins in of circRNA-0074027-downregulated Caco-2 cells following addition of miR-135a-5p. Every experiment was repeated three times. ${ }^{* * *} \mathrm{P}<0.001$. miR, microRNA; circRNA, circular RNA; OD, optical density.

progression of various types of cancer, including glioblastoma and non-small-cell lung cancer. However, no study, to the best of the authors' knowledge, has been performed on the regulatory role of circRNA-0074027 in CRC progression. In the current study, RT-qPCR was performed to detect the expression of circRNA-0074027 in CRC tissue and adjacent normal tissue samples. The results indicated that circRNA-0074027 expression was upregulated in CRC tissues compared with the normal tissues. According to the results of statistical analysis, patients with CRC and circRNA-0074027 overexpression were more likely to have poor differential status, larger tumor size, advanced TNM stage, advanced $\mathrm{N}$ stage and vascular invasion. These results demonstrated that circRNA-0074027 might function as a tumor promoter in the development of CRC.

To clarify the biological role of circRNA-0074027 in CRC progression, circRNA-0074027-downregulated CRC cells were constructed. Results revealed that the deletion of circRNA-0074027 could markedly inhibit cell growth and promote cell apoptosis. However, it remains unclear how circRNA-0074027 participated in the regulation of cell proliferation and apoptosis in CRC. Previous studies report that p53 is a pivotal anti-oncogene in cancer progression and its dysfunction might contribute to the rapid cell proliferation and decreased DNA repair capacity $(25,26)$. circRNA ZNF609 is shown to promote cell apoptosis rate via upregulating p53 expression in CRC (27). Su et al (28) showed that circRNA_0055538 can exert an anti-tumor effect by activating the p53/caspase signaling pathway. The present study also demonstrated that knockdown of circRNA-0074027 increased p53 and Bax proteins expression and decreased Bcl-2 protein expression. Therefore, the silencing of circRNA-0074027 could activate the p53-mediated pathway, which contributes to the suppression of cell proliferation and promotion of cell apoptosis in CRC.

The present study discovered that the patients with CRC and circRNA-0074027 overexpression had advanced N stage, thus it was hypothesized that circRNA-0074027 participated in the regulation of cell migration and invasion ability in CRC. The data of the present study demonstrated that the deletion of circRNA-0074027 could markedly inhibit the cell metastasis ability in $\mathrm{CRC}$, but the potential regulatory mechanism remains to be elucidated. EMT is a significant biological process, in which the epithelial (E) cells transition to a mesenchymal (M) phenotype (29-31). Previous studies indicate that EMT signaling pathway serves an important role in the 
development of malignant tumors (32-34). Wang et al (35) revealed that the circRNA circP4HB can promote cell aggressiveness and metastasis of non-small cell lung carcinoma via sponging miR-133a-5p. In addition, circRNA circPTPRA can sponge miR-96-5p, thereby inhibiting cell metastasis ability in non-small cell lung carcinomas cells via regulating the EMT pathway (36). The results of the present study were consistent with these previous studies and revealed that the downregulation of circRNA-0074027 led to increased expression of epithelial-like phenotype protein (E-cadherin) and decrease expression of mesenchymal phenotype proteins $(\mathrm{N}$-cadherin and vimentin). Taken together, the present study hypothesized that downregulation of circRNA-0074027 mediated inhibition of cell migration and invasion in CRC and this might be caused by the inactivation of EMT signaling pathway.

The primary function of circRNAs is miRNA sponging, which contributes to the carcinogenesis and progression of various types of cancer $(8,37)$.For example, circRNA-MAN2B2 had been identified as a tumor promotor in hepatocellular carcinoma progression via sponging miRNA-217 (38). Another study indicates that circFOXK 2 can sponge miR-942, followed by enhanced cell proliferation, migration and invasion ability in pancreatic ductal adenocarcinoma (39). The present study proposed miR-525-3p as the target gene of circRNA-0074027 in CRC progression. The results of RT-qPCR revealed that miR-525-3p was downregulated in CRC tissues in comparison with normal tissue samples. The Pearson correlation analysis showed that circRNA-0074027 expression was negatively correlated with the expression of miR-525-3p, suggesting that miR-525-3p might be the downstream target gene of circRNA-0074027. The association between the circRNA-0074027 and miR-525-3p was confirmed by dual-luciferase reporter assays. Previous studies identify that miR-525-3p may function as a significant regulatory factor in the development of various types of cancer, including liver cancer (40) and Hodgkin lymphoma (41). Pang et al (40) determined that miR-525-3p can enhance the cell migration and invasion of liver cancer via modulating ZNF395 expression. The results of the current study demonstrated that the addition of miR-525-3p could reverse the anti-tumor effects induced by the silencing of circRNA-0074027. Therefore, these data suggested that circRNA-0074027 could sponge miR-525-3p, thereby participating in the regulation of cell proliferation, cell metastasis and cell apoptosis in CRC. However, the present study has some limitations. First, the molecular targets downstream of the circRNA-0074027/miR-525-3p axis were not fully elucidated. Second, the present study was performed in vitro and there is a need to carry it out in vivo to confirm the biological function of circRNA-0074027. Third, the sample size and the follow-up duration was insufficient. In the future, a large sample size and a longer follow-up duration should be employed to validate the diagnostic and prognostic significance of circRNA-0074027.

CircRNA-0074027 might function as a tumor promoter in CRC, as the patients with CRC and overexpression were more likely to have poor prognosis. In addition, the in vitro experiments indicated that silencing of circRNA-0074027 could directly regulate the function of miR-525-3p and then lead to the suppression of cell proliferation and metastasis ability via interfering with the p53/EMT signaling pathway.
In conclusion, circRNA-0074027 could act as a promising therapeutic bio-marker for CRC.

\section{Acknowledgements}

Not applicable.

\section{Funding}

No funding was received.

\section{Availability of data and materials}

The datasets used and/or analyzed during the current study are available from the corresponding author on reasonable request.

\section{Authors' contributions}

GX and YZ conceived and designed the study. GX, JZ and YZ performed the experiments. GX, XP and BW were responsible for the analysis and interpretation of data. XP, BW and YZ wrote the manuscript. GX and YZ were responsible for confirming the authenticity of the data. All authors read and approved the final manuscript. This manuscript was revised by all authors.

\section{Ethics approval and consent to participate}

Written informed consent was sought from the participants before the samples were obtained. The present study was approved by the Ethical Committees of Dazhou Central Hospital (approval no. KY2020-086-01).

\section{Patient consent for publication}

Not applicable.

\section{Competing interests}

The authors declare that they have no competing interests.

\section{References}

1. Bray F, Ferlay J, Soerjomataram I, Siegel RL, Torre LA and Jemal A: Global cancer statistics 2018: GLOBOCAN estimates of incidence and mortality worldwide for 36 cancers in 185 countries. CA Cancer J Clin 68: 394-424, 2018.

2. Torre LA, Bray F, Siegel RL, Ferlay J, Lortet-Tieulent J and Jemal A: Global cancer statistics, 2012. CA Cancer J Clin 65: 87-108, 2015.

3. Geng F, Wang Z, Yin H, Yu J and Cao B: Molecular targeted drugs and treatment of colorectal cancer: Recent progress and future perspectives. Cancer Biother Radiopharm 32: 149-160, 2017.

4. Roelands J, Kuppen PJK, Vermeulen L, Maccalli C, Decock J, Wang E, Marincola FM, Bedognetti D and Hendrickx W: Immunogenomic Classification of Colorectal Cancer and Therapeutic Implications. Int J Mol Sci 18: 2229, 2017.

5. Su M, Xiao Y, Ma J, Tang Y, Tian B, Zhang Y, Li X, Wu Z, Yang D, Zhou Y, et al: Circular RNAs in cancer: Emerging functions in hallmarks, stemness, resistance and roles as potential biomarkers. Mol Cancer 18: 90, 2019.

6. Memczak S, Jens M, Elefsinioti A, Torti F, Krueger J, Rybak A, Maier L, Mackowiak SD, Gregersen LH, Munschauer M, et al: Circular RNAs are a large class of animal RNAs with regulatory potency. Nature 495: 333-338, 2013. 
7. Cheng J, Zhuo H, Xu M, Wang L, Xu H, Peng J, Hou J, Lin L and Cai J: Regulatory network of circRNA-miRNA-mRNA contributes to the histological classification and disease progression in gastric cancer. J Transl Med 16: 216, 2018.

8. Dori $\mathrm{M}$ and Bicciato S: Integration of bioinformatic predictions and experimental data to identify circRNA-miRNA associations. Genes (Basel) 10: 642, 2019.

9. Wu J, Chen Z, Song Y, Zhu Y, Dou G, Shen X, Zhou Y, Jiang H, Li J and Peng Y: CircRNA_0005075 suppresses carcinogenesis via regulating miR-431/p53/epithelial-mesenchymal transition axis in gastric cancer. Cell Biochem Funct 38 932-942, 2020.

10. Chen Q, Chen Z, Cao S, Guo B, Chen Y, Feng Z, Wang J, Guo G, Chen X and Huang X: Role of CircRNAs_100395 in proliferation and metastases of liver cancer. Med Sci Monit 25: 6181-6192, 2019.

11. Li L, Yu P, Zhang P, Wu H, Chen Q, Li S and Wang Y: Upregulation of hsa circ 0007874 suppresses the progression of ovarian cancer by regulating the miR-760/SOCS3 pathway. Cancer Med 9: 2491-2499, 2020.

12. Zhao J, Li L, Wang Q, Han H, Zhan Q and Xu M: CircRNA expression profile in early-stage lung adenocarcinoma patients. Cell Physiol Biochem 44: 2138-2146, 2017.

13. Cao J and Liu XS: Circular RNA 0060428 sponges miR-375 to promote osteosarcoma cell proliferation by upregulating the expression of RPBJ. Gene 740: 144520, 2020.

14. Yu Q, Dai J and Shu M: Retraction: Hsa_circ_0003645 shows an oncogenic role by sponging microRNA-1299 in hepatocellular carcinoma cells. J Clin Lab Anal 34: e23249, 2020.

15. Qian L, Guan J, Wu Y and Wang Q: Upregulated circular RNA circ_0074027 promotes glioblastoma cell growth and invasion by regulating miR-518a-5p/IL17RD signaling pathway. Biochem Biophys Res Commun 510: 515-519, 2019.

16. Gao P, Wang Z, Hu Z, Jiao X and Yao Y: Circular RNA circ_0074027 indicates a poor prognosis for NSCLC patients and modulates cell proliferation, apoptosis, and invasion via miR-185-3p mediated BRD4/MADD activation. J Cell Biochem 121: 2632-2642, 2020.

17. Livak KJ and Schmittgen TD: Analysis of relative gene expression data using real-time quantitative PCR and the 2(-Delta Delta C(T)) method. Methods 25: 402-408, 2001.

18. Cheng X, Zhang L, Zhang K, Zhang G, Hu Y, Sun X, Zhao C, $\mathrm{Li} \mathrm{H}, \mathrm{Li}$ YM and Zhao J: Circular RNA VMA21 protects against intervertebral disc degeneration through targeting miR-200c and X linked inhibitor-of-apoptosis protein. Ann Rheum Dis 77 770-779, 2018

19. Xu JZ, Shao CC, Wang XJ, Zhao X, Chen JQ, Ouyang YX, Feng J, Zhang F, Huang WH, Ying Q, et al: circTADA2As suppress breast cancer progression and metastasis via targeting miR-203a-3p/SOCS3 axis. Cell Death Dis 10: 175, 2019.

20. Hu W,Han Q,Zhao L and Wang L: Circular RNA circRNA_15698 aggravates the extracellular matrix of diabetic nephropathy mesangial cells via miR-185/TGF- $\beta 1$. J Cell Physiol 234: $1469-1476,2019$

21. Ng WL, Mohd Mohidin TB and Shukla K: Functional role of circular RNAs in cancer development and progression. RNA Biol 15: 995-1005, 2018.

22. Bachmayr-Heyda A, Reiner AT, Auer K, Sukhbaatar N, Aust S, Bachleitner-Hofmann T, Mesteri I, Grunt TW, Zeillinger R and Pils D: Correlation of circular RNA abundance with proliferation-exemplified with colorectal and ovarian cancer, idiopathic lung fibrosis, and normal human tissues. Sci Rep 5: 8057, 2015

23. Qu S, Yang X, Li X, Wang J, Gao Y, Shang R, Sun W, Dou K and Li H: Circular RNA: A new star of noncoding RNAs. Cancer Letts 365: 141-148, 2015.

24. Yu C, Ying J, Yu K, Shen W and Jiang M: Circ 0074027 contributes to nonsmall cell lung cancer progression by upregulating CUL4B expression through miR-335-5p. Cancer Biother Radiopharm: Jun 22, 2020. (Epub ahead of print). doi: $10.1089 /$ cbr.2020.3579.
25. Moch H, Sauter G, Gasser TC, Buchholz N, Bubendorf L, Richter J, Jiang F, Dellas A and Mihatsch MJ: p53 protein expression but not mdm-2 protein expression is associated with rapid tumor cell proliferation and prognosis in renal cell carcinoma. Urol Res 25 (Suppl 1): S25-S30, 1997.

26. Jaber S, Toufektchan E, Lejour V, Bardot B and Toledo F: p53 downregulates the Fanconi anaemia DNA repair pathway. Nat Commun 7: 11091, 2016.

27. Rossi F, Legnini I, Megiorni F, Colantoni A, Santini T, Morlando M, Di Timoteo G, Dattilo D, Dominici C and Bozzoni I: Circ-ZNF609 regulates G1-S progression in rhabdomyosarcoma. Oncogene 38: 3843-3854, 2019.

28. Su W, Sun S, Wang F, Shen Y and Yang H: Circular RNA hsa_circ_0055538 regulates the malignant biological behavior of oral squamous cell carcinoma through the p53/Bcl-2/caspase signaling pathway. J Transl Med 17: 76, 2019.

29. Lee JM, Dedhar S, Kalluri R and Thompson EW: The epithelial-mesenchymal transition: New insights in signaling, development, and disease. J Cell Biol 172: 973-981, 2006.

30. Thiery JP, Acloque H, Huang RYJ and Nieto MA: Epithelialmesenchymal transitions in development and disease. Cell 139: 871-890, 2009.

31. Brabletz T, Kalluri R, Nieto MA and Weinberg RA: EMT in cancer. Nat Rev Cancer 18: 128-134, 2018.

32. Derynck R and Weinberg RA: EMT and cancer: More than meets the eye. Dev Cell 49: 313-316, 2019.

33. Wang Z, Li Y, Kong D and Sarkar FH: The role of Notch signaling pathway in epithelial-mesenchymal transition (EMT) during development and tumor aggressiveness. Curr Drug targets 11: 745-751, 2010.

34. Hu H, Hu S, Xu S, Gao Y, Zeng F and Shui H: miR-29b regulates Ang II-induced EMT of rat renal tubular epithelial cells via targeting PI3K/AKT signaling pathway. Int J Mol Med 42: 453-460, 2018

35. Wang T, Wang X, Du Q, Wu N, Liu X, Chen Y and Wang X: The circRNA circP4HB promotes NSCLC aggressiveness and metastasis by sponging miR-133a-5p. Biochem Biophys Res Commun 513: 904-911, 2019.

36. Wei S, Zheng Y, Jiang Y, Li X, Geng J, Shen Y, Li Q, Wang X, Zhao $\mathrm{C}$, Chen $\mathrm{Y}$, et al: The circRNA circPTPRA suppresses epithelial-mesenchymal transitioning and metastasis of NSCLC cells by sponging miR-96-5p. EBioMedicine 44: 182-193, 2019.

37. Zheng Q, Bao C, Guo W, Li S, Chen J, Chen B, Luo Y, Lyu D, Li Y, Shi G, et al: Circular RNA profiling reveals an abundant circHIPK3 that regulates cell growth by sponging multiple miRNAs. Nat Commun 7: 11215, 2016.

38. Fu X, Zhang J, He X, Yan X, Wei J, Huang M, Liu Y, Lin J, Hu H and Liu L: Circular RNA MAN2B2 promotes cell proliferation of hepatocellular carcinoma cells via the miRNA-217/MAPK1 axis. J Cancer 11: 3318-3326, 2020.

39. Wong CH, Lou UK, Li Y, Chan SL, Tong JHM, To KF and Chen Y: CircFOXK2 promotes growth and metastasis of pancreatic ductal adenocarcinoma by complexing with RNA binding proteins and sponging MiR-942. Cancer Res 80: 2138-2149, 2020.

40. Pang F, Zha R, Zhao Y, Wang Q, Chen D, Zhang Z, Chen T, Yao M, Gu J and He X: MiR-525-3p enhances the migration and invasion of liver cancer cells by downregulating ZNF395. PLoS One 9: e90867, 2014

41. Paydas S, Acikalin A, Ergin M, Celik H, Yavuz B and Tanriverdi K: Micro-RNA (miRNA) profile in Hodgkin lymphoma: Association between clinical and pathological variables. Med Oncol 33: 34, 2016.

This work is licensed under a Creative Commons Attribution-NonCommercial-NoDerivatives 4.0 International (CC BY-NC-ND 4.0) License. 